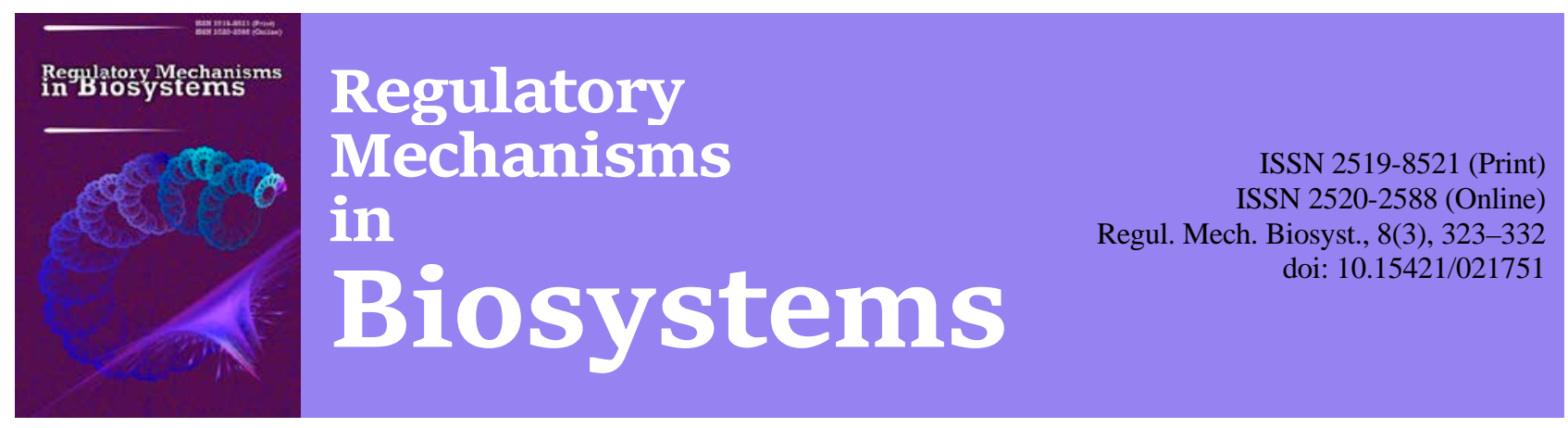

\title{
Structural and functional units of parenchyma of lymph nodes of dromedaries (Camelus dromedarius)
}

\author{
P. N. Gavrilin*, O. G. Gavrilina*, V. V. Brygadyrenko****, D. E. Rahmoun*** \\ *Dnipro State Agrarian-Economic University, Dnipro, Ukraine \\ **Oles Honchar Dnipro National University, Dnipro, Ukraine \\ ***University Bathna 1, Bathna, Algeria
}

Article info

Received 17.06.2017

Received in revised form 22.07.2017

Accepted 28.07.2017

Dnipro State Agrarian-Economic University, Sergey Efremov Str. 25, Dnipro, 49600, Ukraine. Tel.: +38-099-545-33-31. E-mail:

morfologagro@gmail.com

Oles Honchar Dnipro National University, Gagarin Ave., 72, Dnipro, 49010, Ukraine. Tel.: +38-050-939-07-88. E-mail:brigad@ua.fm

University of Batna 1 Institut des Sciences Veterinaires et des sciences agronomiques, Route de Biskra, Batna, Algeria. Tel.: +21-333-31-91-34. E-mail: deddine44@hotmail.com
Gavrilin, P. N., Gavrilina, O. G., Brygadyrenko, V. V., \& Rahmoun, D. E. (2017). Structural and functional units of parenchyma of lymph nodes of dromedaries (Camelus dromedarius). Regulatory Mechanisms in Biosystems, 8(3), 323-332. doi: 10.15421/021751

This article analyzes patterns of structural and functional organization of the parenchyma of different groups of lymph nodes, structural features of their connective tissue frame and lymphatic sinuses. We studied superficial and deep somatic (Limphonodi mandibulares, L. cervicales superficiales, L. axillares proprii, L. poplitei), somatovisceral (L. retropharyngei mediales, $L$. iliaci mediales), visceral ( $L$. mediastinales caudales, $L$. jejunales) features of mature male dromedaries (Camelus dromedarius Linnaeus, 1758). We used a complex of traditional macroscopic and histological techniques, and also immunohistochemical staining of lymph node sections for identifying the features of localization of T- and B-lymphocyte populations in the parenchyma of the nodes. We found that the parenchyma of camels' lymph nodes is characterized by a spongy type structure in the form of a complex of partly concrescent roundoval fragments of lymphoid tissue, surrounded by large lymphatic spaces (sinuses). The connective tissue frame of the lymph nodes is represented by a two-layer (connective tissue-muscular) capsule and two types of trabeculae: twolayered (connective-muscular, type I), which contain blood and lymphatic vessels, as well as lymphatic cysternas, and single-layered, formed only by a smooth muscular system (type II). Intranodal lymphatic sinuses are subdivided into subcapsular, peritrabecular and medullary sinuses. The subcapsular sinuses and sinuses related to trabeculae of type I and their branching is the most developed. At the tissue level, the lymph node parenchyma has a clearly manifested lobular structure. Lymphoid lobules in the lymph node parenchyma are positioned diffusely (mosaically) and consist of four main cellular zones: transit and cell-cell interaction (analogous to the cortical plateau), clonal proliferation of Tand, respectively, B-lymphocytes (deep cortex units, lymphatic nodules), accumulation of plasmocytes and synthesis of antibodies (brain cords). The lymphoid lobes (compartments) of the lymph nodes parenchyma are bipolar, their tops formed by the zones of transit and cell-cell interaction, and also by the zones of proliferation of B lymphocytes, and the bases by a complex of brain cords (zone of accumulation of plasmocytes and synthesis of antibodies). The zone of T-lymphocytes proliferation is in intermediate position and underlies the subunits of the parenchyma. The tops of the lymphoid lobes are located along the sinuses of the trabeculae of type I and the bases along the sinuses of the trabeculae of type II, which form the efferent lymphatic vessels. The maximum relative capacity of all studied lymph nodes was typical for zones of plasmocyte accumulation and synthesis of antibodies (19-27\%), the minimum capacity was typical for transit and cell-cell interaction zones (3-8\%). The relative capacity of zones of clonal proliferation of T- and B-lymphocytes in most lymph nodes was 1.5-3.0 times less than that of the zone of plasmocyte accumulation and antibody formation and was, respectively, 8-16\% and 9-18\%. The study showed that the structure of the lymph nodes parenchyma of dromedaries is not absolutely unique. As in other mammal species, it is subdivided into specialized cell zones which are connected in lymphoid lobules. Specific features of parenchyma structure include: diffuse (mosaic) location of lymphoid lobules; absence of signs of regulated localization of lymphoid lobules relative to the capsule and the sinus bordering the nodes.

Keywords: compartments; lymphoid lobules; lymphatic nodules; deep cortex units; medullary cords

\section{Структурно-функциональные единицы паренхимы лимфатических узлов одногорбого верблюда (Camelus dromedarius)}

\author{
П. Н. Гаврилин*, Е. Г. Гаврилина*, В. В. Бригадиренко****, Д. Э. Рахмун***
}


*Днепровский государственный аграрно-экономический университет, Днепр, Украина

**Днепровский национальный университет имени Олеся Гончара, Днепр, Украина

***Университет Батны 1, Батна, Алжир

Проанализирована структура паренхимы, соединительнотканного остова и лимфатических синусов в лимфатических узлах самцов половозрелого одногорбого верблюда (Camelus dromedarius Linnaeus, 1758). Использовали комплекс макроскопических, классических гистологических методик и иммуногистохимическое окрашивание срезов лимфатических узлов. Макроскопически паренхима лимфатических узлов имеет губкообразный тип строения в виде округло-овальных фрагментов лимфоидной ткани, разделенных широкими синусами. Внутриузловой соединительнотканный остов представлен трабекулами двух типов: соединительнотканно-мышечными (I тип) и гладкомышечными (II тип). Лимфатические синусы подразделяются на широкие подкапсулярные и перитрабекулярные трабекул I типа, а также менее развитые - перитрабекулярные трабекул II типа и мозговые. Микроскопически лимфоидная ткань лимфатических узлов состоит из диффузно расположенных (мозаичных) скоплений лимфоидных долек, каждая из которых образована четырьмя специализированными клеточными зонами. Вершины лимфоидных долек представлены зонами транзита и межклеточного взаимодействия и лимфатическими узелками (В-зоны), основания - комплексом мозговых тяжей (зоны аккумуляции плазмоцитов и антителообразования), центры - единицами глубокой коры (Т-зоны). Зоны транзита и межклеточного взаимодействия лимфоидных долек ориентированы вдоль синусов трабекул I типа, а основания долек - вдоль синусов трабекул II типа. Наиболее развитыми клеточными зонами лимфоидных долек являются мозговые тяжи (относительный объем - 19-27\%), а наименее - зоны транзита и межклеточного взаимодействия (аналоги коркового плато, относительный объем - 3-8\%). Объем зон клональной пролиферации Т- и В-лимфоцитов в 1,5-3,0 раза меньше объема мозговых тяжей, 8-16\% и 9-18\%, соответственно.

Ключевые слова: компартменты; лимфоидные дольки; лимфатические узелки; единицы глубокой коры; мозговые тяжи

\section{Введение}

На сегодняшний день не вызывает сомнения факт, что для паренхимы лимфатических узлов млекопитающих характерна высокая степень упорядоченности, которая заключается в зональной специализации и интеграции отдельных клеточных зон (Kelly, 1975; Konenkov et al., 2008; Butler et al., 2016).

Дискретная структура паренхимы лимфатических узлов млекопитающих является морфологическим проявлением целого комплекса процессов, которые развиваются во время реализации функции иммунологической реактивности: миграции, кооперации, клональной пролиферации различных типов иммунокомпетентных клеток, а также антителообразования (Kowala and Schoefi, 1986; Konenkov et al., 2008; Margaris and Black, 2012).

Особенности морфофункциональной дифференциации и интеграции паренхимы лимфатических узлов обусловлены в равной степени структурой их кровеносного и лимфатического русел. Кровеносные сосуды обеспечивают процесс односторонней миграции лимфоцитов из крови в паренхиму узлов, а лимфатические сосуды и синусы - беспрепятственную многовекторную миграцию антигенпрезентирующих и иммунокомпетентных клеток между лимфатическими пространствами и лимфоидными структурами узлов (Ikomi et al., 2012; Chandrasecaran and King, 2014).

Транзит лимфоцитов через стенки венул с высоким эндотелием осуществляется в периферических участках глубокой коры лимфатических узлов (паракортикальные тяжи), а также в корковом плато (интерфолликулярная зона). В этих же зонах паренхимы осуществляется взаимодействие (премирование) лимфоцитов с антигенпрезентирующими клетками (De Bruyn and Cho, 1990; Platt and Randolph, 2013; Ruddle, 2016; Ager, 2017).

Зоны клональной пролиферации премированных лимфоцитов в паренхиме лимфатических узлов представлены сферообразными структурами двух различных типов: лимфатическими узелками (В-зоны), которые формируются вдоль лимфатических синусов на основе коркового плато и относительно крупными округлоовальными образованиями или единицами глубокой коры (Т-зоны), расположенными в центральных участках паренхимы, которые непосредственно не контактируют с системой внутриузловых синусов (Kaldjian et al., 2001; Katakai et al., 2004; Palm et al., 2016). Концентрация плазматических клеток и антителообразование происходит в мозговых тяжах, занимающих пространство между глубокой корой и воротами узлов и образующих в совокупности мозговое вещество лимфатических узлов (Andrian and Mempel, 2003; Olson et al., 2012; Houston et al., 2016).

Структурным проявлениям интегративных процессов в паренхиме лимфатических узлов является формирование на ее основе ряда идентичных по гистоархитектонике образований, включающих все вышеуказанные клеточные зоны. Данные субъединицы в лимфатических узлах млекопитающих обозначаются как компартменты или лимфоидные дольки (Gretz, 1997; Willard-Mack, 2006; Sainte-Marie, 2010). Дольчатая структура лимфатических узлов формируется у млекопитающих в процессе эмбриогенеза в результате внедрения множества мезенхимных почек в просвет лимфатических синусов (Mebius, 2003). В дефинитивном лимфатическом узле каждой дольке его паренхимы соответствует один афферентный лимфатический сосуд (Sainte-Marie, 2010).

Общепринятое на сегодня представление о лимфоидной дольке (компартменте) лимфатических узлов было разработано на основе исследования зональной структуры паренхимы данных органов у приматов и некоторых видов лабораторных животных (Belisle and Sainte-Marie, 1981; Ikomi et al., 2012; Butler et al., 2016). Характерными чертами строения данных субъединиц являются: четко выраженная морфологическая полярность с локализацией лимфатических узелков и мозговых тяжей на противоположных полюсах компартментов и их упорядоченное линейное расположение вдоль краевого синуса узлов, что придает паренхиме лимфатических узлов слоистую структуру (Gunnes et al., 1998; Iwasaki et al., 2016).

Проведенные впоследствии более широкие исследования закономерностей строения паренхимы лимфатических узлов у различных видов млекопитающих с разной организацией основных жизнеобеспечивающих систем показали, что вышеуказанное представление о структуре компартментов паренхимы лимфатического узла не является универсальным.

При исследовании лимфатических узлов быка домашнего установлено, что, несмотря на наличие в данных органах явных признаков упорядоченного дольчатого строения паренхимы, морфологическая полярность в лимфоидных дольках не наблюдается, что связано с особым характером локализации лимфатических узелков в пределах компартментов, в которых узелки формируются как на основе коркового плато, так и в паракортикальных и мозговых тяжах (Gavrilin et al., 2013, 2017).

В болышинстве работ, посвященных описанию структуры лимфатических узлов верблюда, млекопитающего, отличающегося наличием наиболее совершенных механизмов адаптации в чрезвычайно сложных природно-климатических условиях, указывается, что паренхима узлов подразделяется на ряд специализированных участков, но какая-либо определенная закономерность в их взаиморасположении и локализации в целом в паренхиме узла отсутствует (Abdel-Magied et al., 2001; Zidan, 2002; Zidan and Pabst, 2012). Известно также, что разноуровневый или гнездовой принцип локализации компартментов в лимфатических узлах свиньи домашней связан со специфической структурой капсулы узлов, которая образует многочисленные складки и инвагинации, глубоко внедряющиеся в их паренхиму. Кроме того, внутри складок капсулы располагаются лимфатические цистерны и интратрабекулярные лимфатические каналы, которые обеспечивают одномоментное равномерное поступление лимфы как в поверхностные, 
так и в глубокие синусы узлов (Hoshi et al., 1986; Gavrilin et al., 2014). Существующие на сегодня противоречия в отношении общих закономерностей морфофункциональной дифференциации и специализации паренхимы лимфатических узлов млекопитающих препятствуют развитию и окончательному утверждению в морфологии концепции о ее универсальном дольчатом (компартментном) строении, что, в свою очередь, негативно отражается на понимании и интерпретации изменений в данных органах в норме, при экспериментальных воздействиях и развитии различных патологий. Решение данной проблемы заключается в проведении комплексного сравнительного анализа строения лимфатических узлов у представителей всех основных когорт млекопитающих с учетом степени морфологической сложности и эволюционной иерархии.

Цель исследований - определить закономерности структуры паренхимы лимфатических узлов половозрелого одногорбого верблюда в связи с особенностями строения соединительнотканного остова и внутриузлового лимфатического русла.

\section{Материал и методы исследований}

Образцы для исследования получены от 10 половозрелых трехлетних клинически здоровых самцов одногорбого верблюда после убоя животных на мясокомбинате г. Уаргла (Алжир). Материал исследования - лимфатические узлы различной локализации: поверхностные соматические: нижнечелюстные (Limphonodi mandibulares), поверхностные шейные (L. cervicales superficiales); глубокие соматические: подмышечные (L. axillares proprii), подколенные (L. poplitei); висцеральные: каудальные средостенные (L. mediastinales caudales), тощей кишки (L. jejunales); смешанные или сомато-висцеральные: медиальные заглоточные $(L$. retropharyngei mediales), медиальные подвздошные (L. iliaci mediales) (Zelenevsky, 2013). Всего исследовано 140 органов, так как соматические и сомато-висцеральные узлы являются парными, а висцеральные - непарными.

С целью выяснения особенностей строения и архитектоники системы лимфатических пространств лимфатических узлов осуществляли непрямую инъекцию лимфатического русла дистальных отделов грудной и тазовой конечностей суспензией черной туши на 3\% желатиновом геле (Kostiyk, 2008). После наполнения соответствующей контрастной массой синусов региональных лимфатических узлов конечностей (подмышечный, подколенный) органы рассекали в различных плоскостях и проводили макроскопическую оценку степени развития и особенностей строения внутриузлового лимфатического русла.

При отборе материала для гистологических исследований учитывали особенности макроскопической структуры лимфатических узлов верблюда, которые представляют собой конгломераты из частично сросшихся между собой субъединиц без определенной закономерности в их взаиморасположении (Gavrilin et al., 2015). Для исследований от каждого лимфатического узла отбирали по 6 наиболее развитых и обособленных субъединиц. Из отобранных субъединиц вырезали тотальные фрагменты в сегментальной плоскости, фиксировали в $10 \%$ растворе нейтрального забуференного формалина.

После фиксации часть фрагментов (по 3 фрагмента) лимфатических узлов заливали в парафин (гистопласт). Парафиновые срезы толщиной 3-5 мкм окрашивали гематоксилином и эозином (по Ван-Гизон), а также использовали для иммуногистохимических исследований. Иммуногистохимические исследования проводили прямым методом Кунса по методике Rodney and Miller (Rodney, 2001). Использовали первичные кроличьи моноклональные антитела, которые дают перекрестные реакции с лейкоцитами верблюда (антитела к $\mathrm{CD}_{3}$ антигену (общие Т-лимфоциты) антитела к $\mathrm{CD}_{22}$ антигену (В-лимфоциты)). Иммуногистохимический анализ состоял из следующих основных стадий: ингибиция эндогенной пероксидазы (гидроген пероксид в метаноле); демаскировка антигенов (Tris + ЕДТА), инкубация с первичными моноклональными кроличьими антителами $\left(\mathrm{CD}_{3}, \mathrm{CD}_{22}\right)$; обработка стрептавидином, конъюгированным с пероксидазой; обработка PBS
(рН 7,2), содержащим 0,05\% 3,3-диаминобензидинтетрагидрохлорид и $0,03 \%$ перекись водорода; окраска гематоксилином Майера.

Другую часть фрагментов лимфатических узлов использовали для изготовления замороженных срезов на микротоме-криостате. Замороженные срезы импрегнировали нитратом серебра по методике Фута в авторской модификации (Gavrilin, 1999), что давало возможность для одновременной четкой визуализации всех основных компонентов паренхимы лимфатических узлов, которая обусловлена специфической для каждой зоны паренхимы архитектоникой сетей ретикулярных волокон.

Исследование гистопрепаратов проводили с использованием световых мироскопов Olympus CX-41 и Leica DM 1000 (окуляр ${ }^{\mathrm{x}} 10$, объективы $\left.{ }^{\mathrm{x}} 10,{ }^{\mathrm{x}} 40\right)$. В гистопрепаратах, окрашенных гематоксилином и еозином, азур-II еозином, по Ван-Гизон, а также иммуногистохимически определяли комплекс качественных характеристик исследуемых органов: степень развития и дифференцировки стромы и паренхимы узлов, особенности гистоархитектоники паренхимы, характер взаимоотношений отдельных компонентов в паренхиме узлов, принципы локализации в паренхиме узлов популяций Т- и В-лимфоцитов.

В гистопрепаратах, импрегнированных нитратом серебра, определяли процентную объемную плотность или относительный объем (V, \%) стромы (капсула, трабекулы), синусов и лимфоидной ткани в лимфатических узлах в целом, а также особенности локализации лимфоидных долек на всей площади тотальных срезов и совокупный относительный объем их отдельных структурных компонентов: зона транзита и межклеточного взаимодействия (периферические участки единиц глубокой коры), зона клональной пролиферации Т-лимфоцитов (центральная зона единиц глубокой коры), зона клональной пролиферации В-лимфоцитов (лимфатические узелки), зона аккумуляции плазмоцитов и синтеза антител (мозговые тяжи).

Количественный анализ вышеуказанных компонентов проводили методом «точечного счета» (Avtandilov, 1990) с использованием окулярных тестовых систем с нанесенными равноудаленными точками (100 точек) на всей площади гистопрепарата. Относительный объем структурных компонентов лимфоидной паренхимы лимфатических узлов вычисляли по формуле:

$$
V_{i}=P_{i} / P_{t} \cdot 100 \% \text {, }
$$

где $V_{i}$ - относительный объем структурного компонента, $P_{i}-$ число точек, попавших на структурный компонент, $P_{t}-$ общее число точек тестовой системы, попавших на гистопрепарат.

Необходимое для получения достоверных данных число точек ñ (минимальный размер выборки, при котором выборочные наблюдения отклоняются от значений для генеральной совокупности не ниже чем на $5 \%$ ), определяли по формуле:

$$
\tilde{n}=400(100-n) / n,
$$

где $n$ - число точек, приходящихся на анализируемый компонент при предварительном подсчете 100 точек (Avtandilov, 1990).

Измерения проводили на световом микроскопе Olympus CX-41 (объектив ${ }^{\mathrm{x}} 10 / 0,25 ;{ }^{\mathrm{x}} 40 / 0,65$ ). Макрофотографии изготавливали с помощью фотокамеры Canon, а микрофотографии - c использованием микроскопов Leica DM 1000 (окуляр ${ }^{4}$, объектив x $\left.10 / 0,25,{ }^{x} 40 / 0,65\right)$, интегрированного с персональным компьютером и Olimpus CX-41.

Результаты исследований статистически обработаны и представлены с помощью Statistica 12.0 (StatSoft Inc., USA). Вероятность разницы значений в различных группах лимфатических узлов оценивали при помощи t-критерия Стьюдента $(\mathrm{P}<0,05)$ после проверки нормальности распределения и разницы между генеральными дисперсиями.

\section{Результаты и их обсуждение}

При макроскопическом исследовании тотальних срезов лимфатических узлов после наполнения их лимфатических пространств (синусов) тушью установлено, что паренхима данных органов у верблюда одногорбого отличается уникальной губчатой структурой. В отличие от большинства видов млекопитающих, у 
которых лимфоидная паренхима в лимфатических узлах «концентрируется» вдоль краевого синуса и максимально приближена к устью афферентных лимфатических сосудов, в соответствующих органах верблюда она равномерно распределена по всей площади среза узлов и состоит из комплекса незавершенных долек и тяжей лимфоидной ткани, ограниченных широкими лимфатическими пространствами (рис. 1).

Формирование губчато-островковой структуры паренхимы в лимфатических узлах одногорбого верблюда может быть обусловлено особым типом строения их стромального каркаса и внутриузлового лимфатического русла. Соединительнотканная строма узлов представлена капсулой и комплексом ее многочисленных производных или трабекул. Капсула лимфатических узлов верблюда имеет четко выраженное двухслойное строение. Ее внешний слой образован, преимущественно, плотной волокнистой неоформленной соединительной тканью, а внутренний - гладкой мускулатурой (Taher et al., 1989; Abdel-Magied, 2001; Zidan and Pabst, 2011). Трабекулы, в отличие от капсулы, подразделяются на два основних типа: двухслойные (соединительнотканно-мышечные) и однослойные (мышечные) (рис. 2). Трабекулы I типа отходят непосредственно от капсулы в виде ее мощных складок или инвагинаций, глубоко внедряются в паренхиму узлов, формируя древовидные внутриузловые разветвления. Трабекулы II типа могут быть производными внутреннего слоя капсулы или капсулярных трабекул I типа. Они являются более мелкими и многочисленными. Капсула и капсулярные трабекулы лимфатических узлов верблюда сопровождаются широкими, субкапсулярными и перитрабекулярными синусами, что придает паренхиме узлов характерную дискретную структуру в виде комплекса незавершенных лимфоидных долек, окруженных относительно равномерной сетью широких лимфатических пространств. При исследовании динамики относительного объема стромы в лимфатических узлах установлено, что соединительнотканный остов достаточно хорошо развит во всех исследованных органах. При этом максимальный относительный объем капсулы и трабекул характерен для соматических, особенно подкожных, лимфатических узлов (рис. 3).

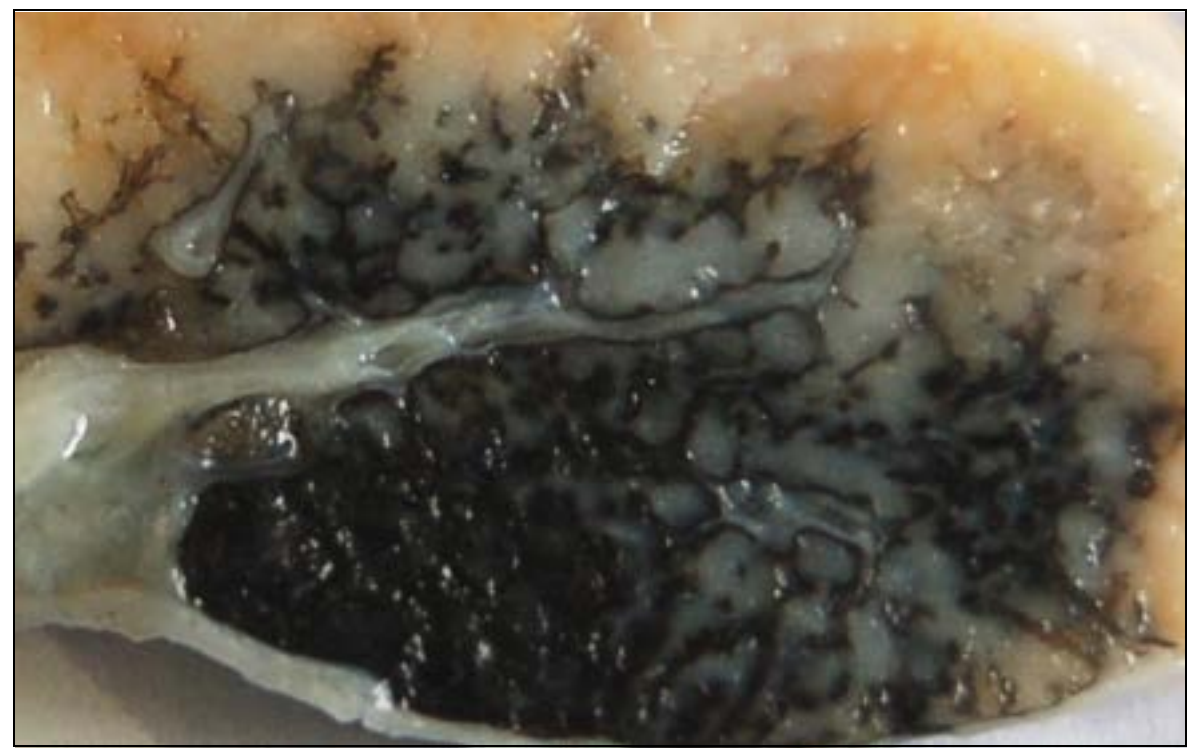

Рис. 1. Синусы подколенного лимфатического узла одногорбого верблюда, заполненные контрастной массой (суспензия черной туши на $3 \%$ желатиновом геле)

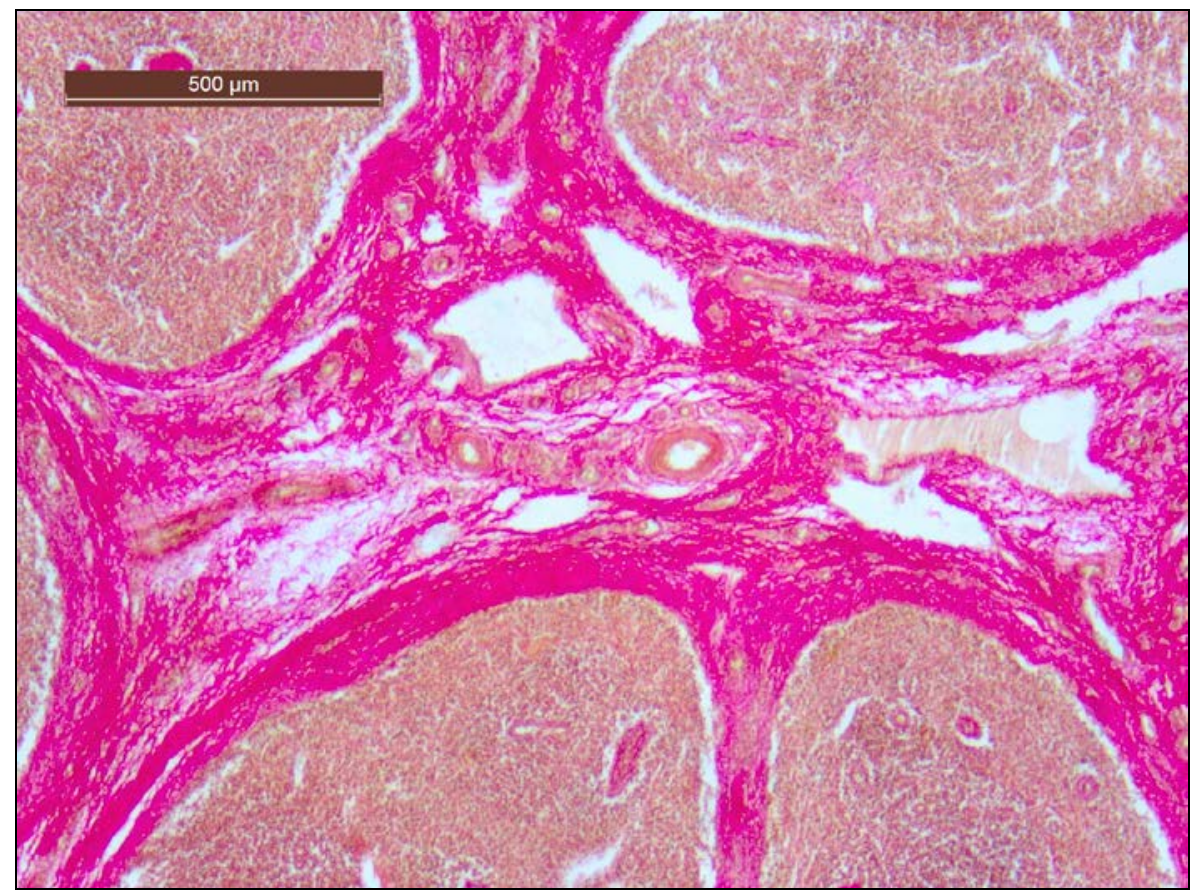

Рис. 2. Трабекулы соединительнотканно-мышечного типа в паренхиме нижнечелюстного лимфатического узла: окраска по Ван-Гизон 
В более глубоких сомато-висцеральных и висцеральных лимфатических узлах относительный объем стромы существенно меньше, чем в соматических узлах обеих групп, за исключением медиального подвздошного узла, относительный объем капсулы и трабекул которого достоверно не отличается от соответствующего показателя глубоких соматических узлов. Учитывая тот факт, что основная масса синусов в лимфатических узлах верблюда располагается вдоль капсулы и трабекул, динамика их совокупного относительного объема в узлах различных групп четко взаимосвязана с изменениями объема стромы данных органов. Так, в большинстве как соматических, так и висцеральных лимфатических узлов относительный объем стромы и синусов практически равнозначен или незначительно отличается, в пределах 4-7\% (рис. 4).

Исключением являются медиальный подвздошный лимфатический узел и лимфатический узел тощей кишки, где относительный объем синусов в 2,0-2,5 раза меньше, чем объем капсулы и трабекул.
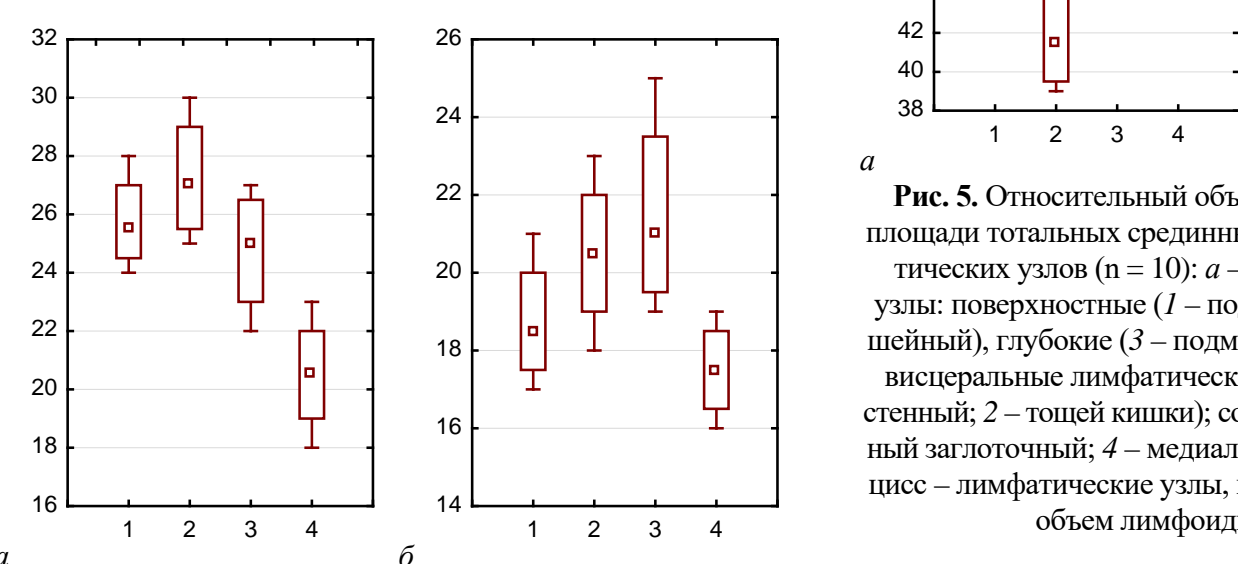
6

Рис. 3. Относительный объем стромы (капсулы и трабекул) на площади тотальных срединных сегментальных срезов лимфатических узлов (n = 10): $a$ - соматические лимфатические узлы: поверхностные (1 - подчелюстной, 2 - поверхностный шейный), глубокие (3 - подмышечный, 4 - подколенный); $\sigma$ - висцеральные лимфатические узлы (1 - каудальный средостенный, 2 - тощей кишки); сомато-висцеральные (3 - медиальный заглоточный; 4 - медиальный подвздошный); по оси абсцисс - лимфатические узлы, по оси ординат - относительный объем стромы (\%)

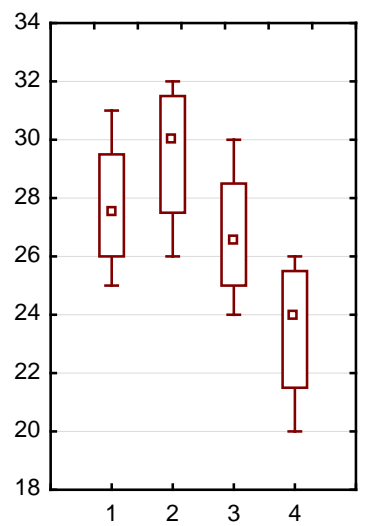

$a$

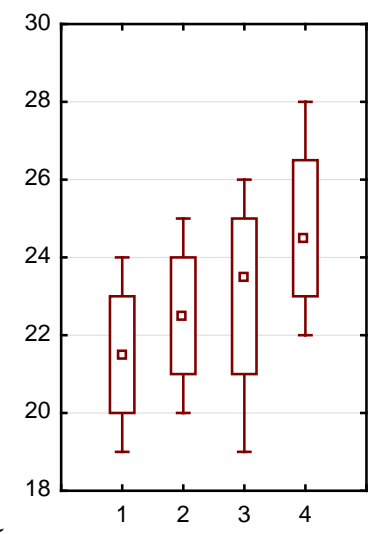

$\sigma$

Рис. 4. Относительный объем синусов на площади тотальных срединных сегментальных срезов лимфатических узлов $(\mathrm{n}=10)$ :

$a$ - соматические лимфатические узлы: поверхностные (1 -

подчелюстной, 2 - поверхностный шейный), глубокие (3 подмышечный, 4 - подколенный); б - висцеральные лимфатические узлы (1 - каудальный средостенный; 2 - тощей кишки); сомато-висцеральные (3 - медиальный заглоточный; 4 - медиальный подвздошный); по оси абсцисс - лимфатические узлы, по оси ординат - относительный объем синусов (\%) $a$

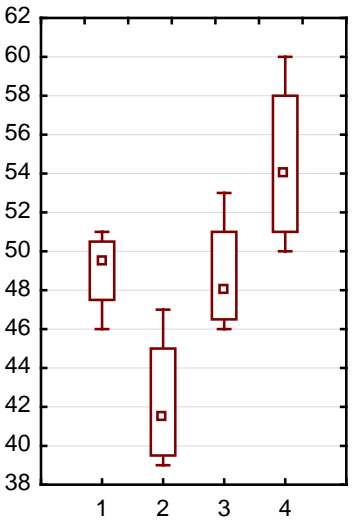

Рис. 5. Относительный объем лимфоидной паренхимы на площади тотальных срединных сегментальных срезов лимфатических узлов (n = 10): $a$ - соматические лимфатические узлы: поверхностные (1 - подчелюстной, 2 - поверхностный шейный), глубокие (3 - подмышечный, 4 - подколенный); 6 висцеральные лимфатические узлы (1 - каудальный средостенный; 2 - тощей кишки); сомато-висцеральные (3 - медиальный заглоточный; 4 - медиальный подвздошный); по оси абсцисс - лимфатические узлы, по оси ординат - относительный

Вследствие значительного развития соединительнотканного остова и системы синусов относительный объем паренхимы вышает 57\% с максимальным значением данного показателя в висцеральных и сомато-висцеральных узлах, и минимальным в поверхностных соматических (рис. 5).

$$
\text { объем лимфоидной паренхимы (\%) }
$$

При исследовании серии гистопрепаратов лимфатических узлов, окрашенных гематоксилином и эозином, по Ван-Гизон, а также импрегнированных нитратом серебра, нами установлено, что паренхима данных узлов имеет зональную структуру. При этом отдельные клеточные зоны объединяются в идентичные по строению дольки, характер локализации которых определяется особенностями развития и архитектоники различных типов трабекул и, соответственно, перитрабекулярных синусов (рис. 6). Основания лимфоидных долек направлены в сторону перитрабекулярных синусов трабекул I типа, а их противоположные полюса («вершины») граничат с соответствующими синусами трабекул II типа.

Архитектоника сетей ретикулярных волокон краевых участков паренхимы, которые непосредственно граничат с синусами, расположенными вдоль трабекул I типа, аналогична ретикулярным сетям в корковом плато (интерфолликулярной зоне) лимфатических узлов у большинства других видов млекопитающих. Интерфолликулярная зона вместе с паракортикальными тяжами относится к зоне транзита и межклеточного взаимодействия (взаимодействие лимфоцитов с антигенпрезентирующими клетками). Для данной зоны характерна среднепетлистая ретикулярная сеть с наличием значительного количества грубых волокнистых тяжей, которые пронизывают перитрабекулярные синусы и достигают внутреннего слоя трабекул. В зоне транзита располагаются многочисленные широкие сосуды, которые относятся к венулам с высоким эндотелием (De Bruyn and Cho, 1990; Ruddle, 2016).

Вглубь от зон транзита и межклеточного взаимодействия располагаются сферообразные участки лимфоидной паренхимы, ретикулярная строма которых имеет равномерную сотовидную крупнопетлистую архитектонику. Большая часть лимфоидных о том, что данный участок паренхимы представляет собой очаг клональной пролиферации соответствующей популяции лимфоцитов (рис. 7). В лимфатических узлах представителей различных видов млекопитающих с классической слоистой структурой клеток данной зоны относится к Т-клеткам, что свидетельствует 
паренхимы зона пролиферации Т-лимфоцитов вместе с паракортикальными тяжами, которые находятся на их периферии, формируют так называемые единицы глубокой коры (Belisle and Sainte-Marie, 1981; Vyrenkov et al., 1995). Единицы глубокой коры располагаются цепочкой между корковым плато и мозговыми тяжами и в совокупности образуют глубокую кору узлов. В паренхиме лимфатических узлов верблюда аналогичные структу- ры отличаются менее упорядоченным характером расположения вдоль перитрабекулярных синусов трабекул I типа и их крупных ветвей, от которых они ограничены зонами транзита и межклеточного взаимодействия, которые охватывают данные структуры полукольцом (рис. 8). Свободный внутренний участок единиц глубокой коры граничит с мозговыми тяжами и образует кортико-медуллярное соединение.

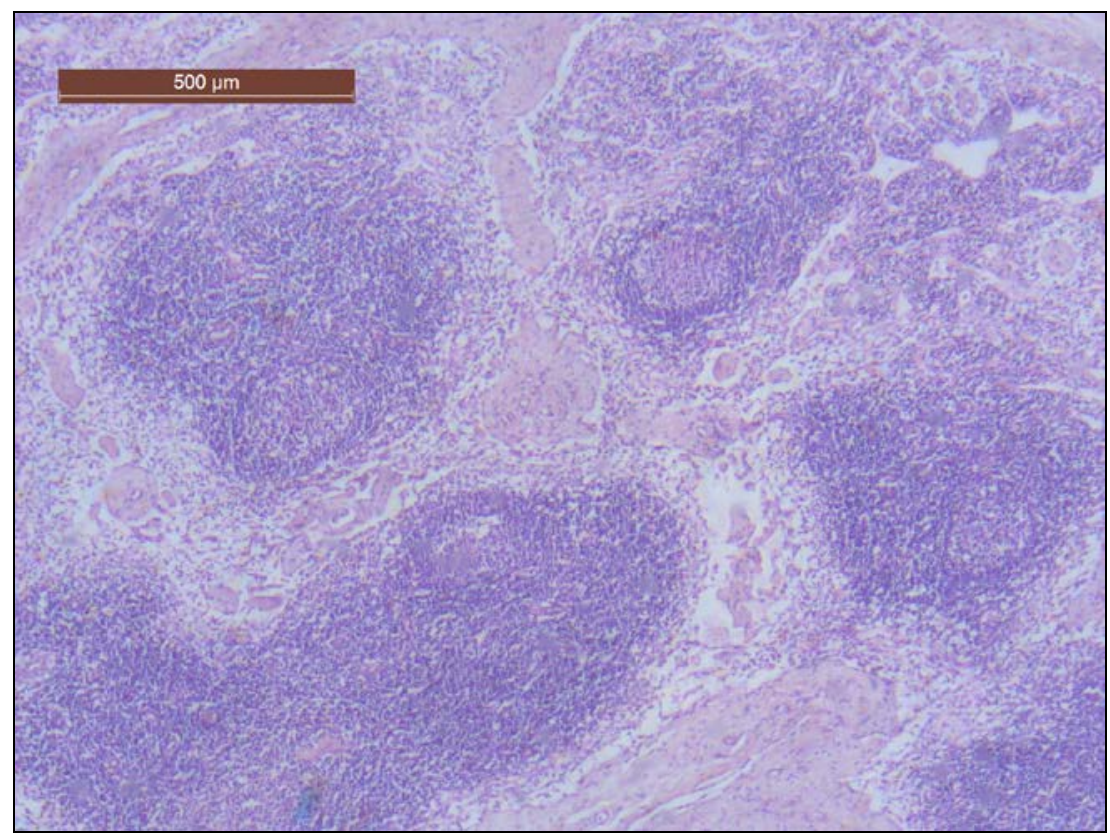

Pис. 6. Лимфоидные дольки в паренхиме лимфатического узла верблюда: окраска гематоксилином и эозином

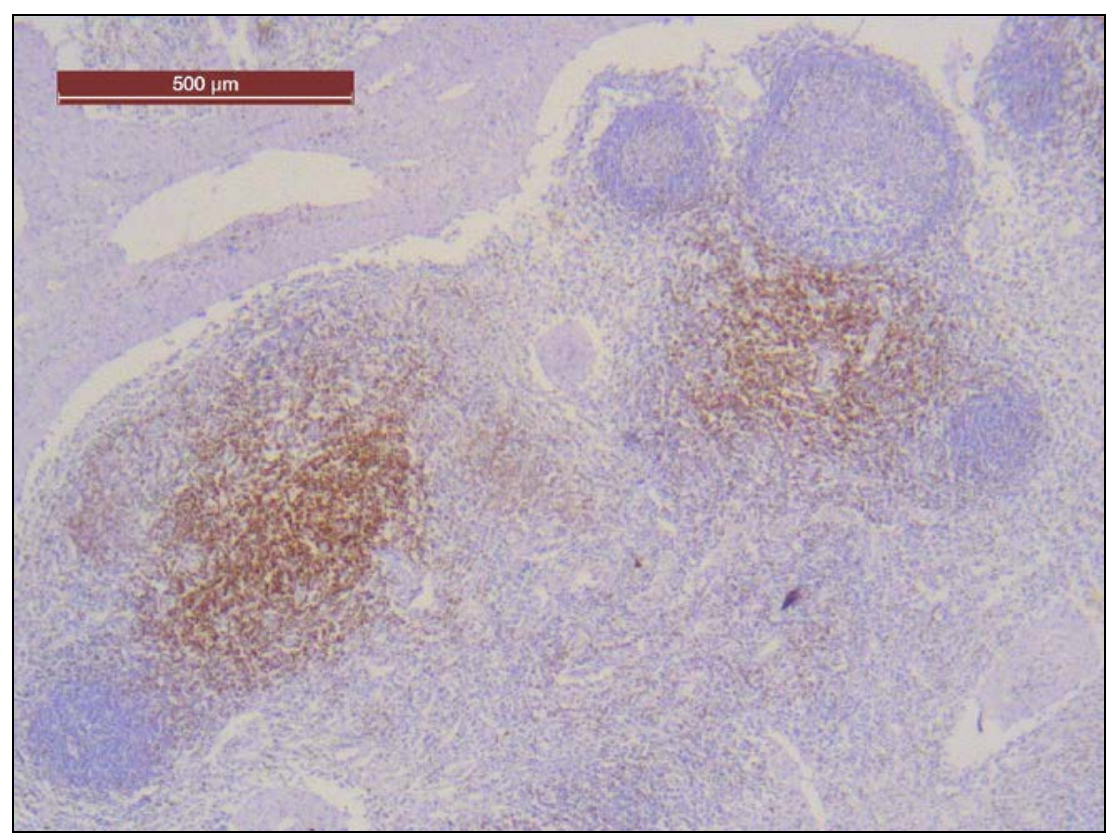

Рис. 7. Скопления Т-лимфоцитов $\left(\mathrm{CD}_{22}\right)$ в паренхиме лимфатического узла: иммуногистохимическое окрашивание, окраска гематоксилином Майера

Мозговые тяжи имеют характерную мелкоячеистую структуру ретикулярного остова, между мозговыми тяжами располагаются многочисленные узкие мозговые синусы. На основе зон транзита формируются лимфатические узелки, большая часть клеток которых относится к популяции В-лимфоцитов. Уникальность структуры лимфатических узелков в лимфатических узлах верблюда связана с наличием в составе их стромы многочисленных гладкомышечных клеток, которые в узелках со светлыми центрами размножения формируют специфические гладкомышечные капсулы, вероятно, обладающие со- кратительной способностью. Сети ретикулярных волокон в лимфатических узелках развиты, преимущественно, на их периферии в мантийных зонах в виде ретикулярных «корзиночек». В центрах узелков обнаруживаются редкие крупнопетлистые сети или отдельные фрагменты ретикулярных волокон (рис. 9). Таким образом, паренхима лимфатических узлов верблюда имеет зональную структуру. Отдельные клеточные зоны интегрируются в лимфоидные дольки или компартменты, архитектоника и принцип расположения которых имеют ряд характерных отличий. Так же, как и в лимфатических узлах лабораторных 
животных и приматов, основой каждой лимфоидной дольки в лимфатических узлах верблюда являются сферообразные зоны пролиферации Т-лимфоцитов, а их периферия на одном из полюсов представлена зоной транзита и межклеточного взаимодействия и лимфатическими узелками, а на другом - комплексом мозговых тяжей. В то же время лимфоидные дольки в паренхиме лимфатических узлов верблюда расположены диффузно без каких-либо четких признаков упорядоченности, что придает паренхиме характерный мозаичный рисунок. Наряду с пространствен- ной неупорядоченностью в паренхиме лимфатических узлов верблюда наблюдаются определенные закономерности в расположении лимфоидных долек относительно перитрабекулярных синусов трабекул различных типов. Наши исследования показывают, что транзитные зоны лимфоидных долек с лимфатическими узелками ориентированы, преимущественно, вдоль перитрабекулярных лимфатических синусов трабекул I типа с их разветвлениями, а в зоне расположения мозговых тяжей находятся в основном трабекулы II типа.

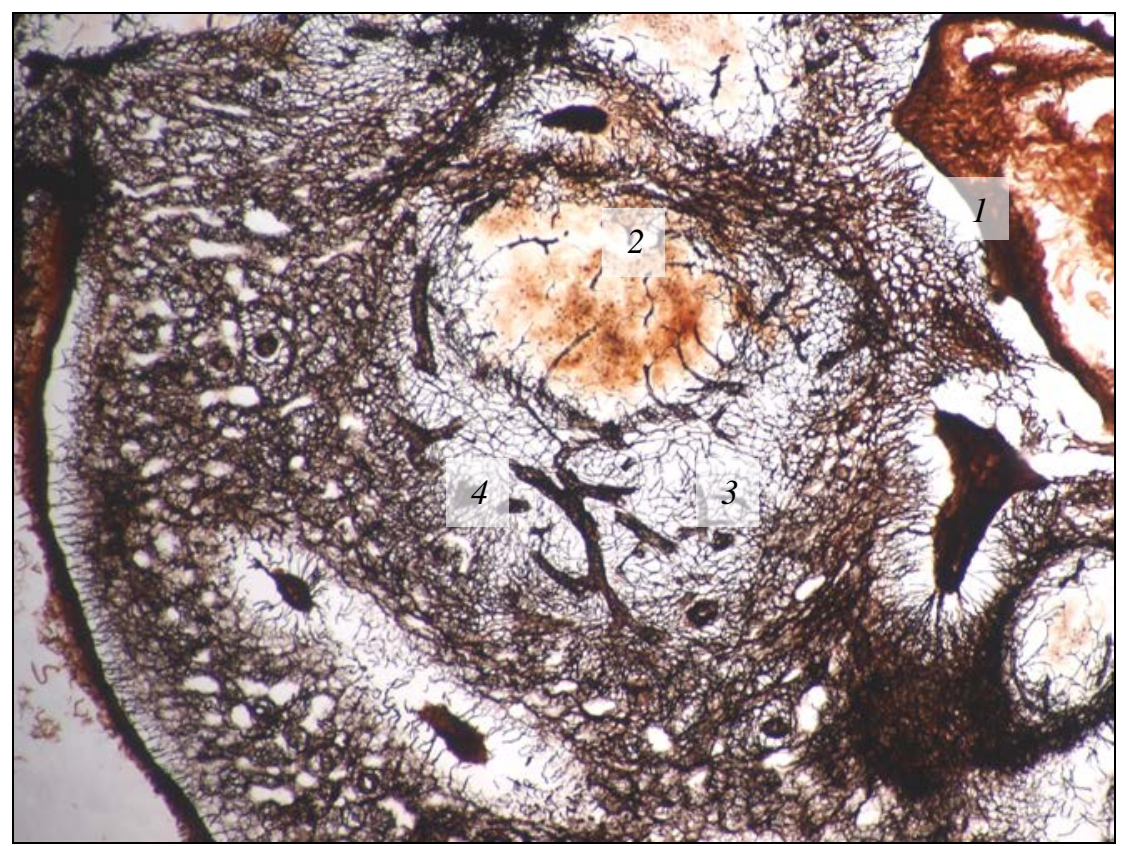

Рис. 8. Компартмент паренхимы подчелюстного лимфатического узла: зона транзита и межклеточного взаимодействия (1), лимфатический узелок (2), единицы глубокой коры (3), мозговые тяжи (4); импрегнация азотнокислым серебром 100

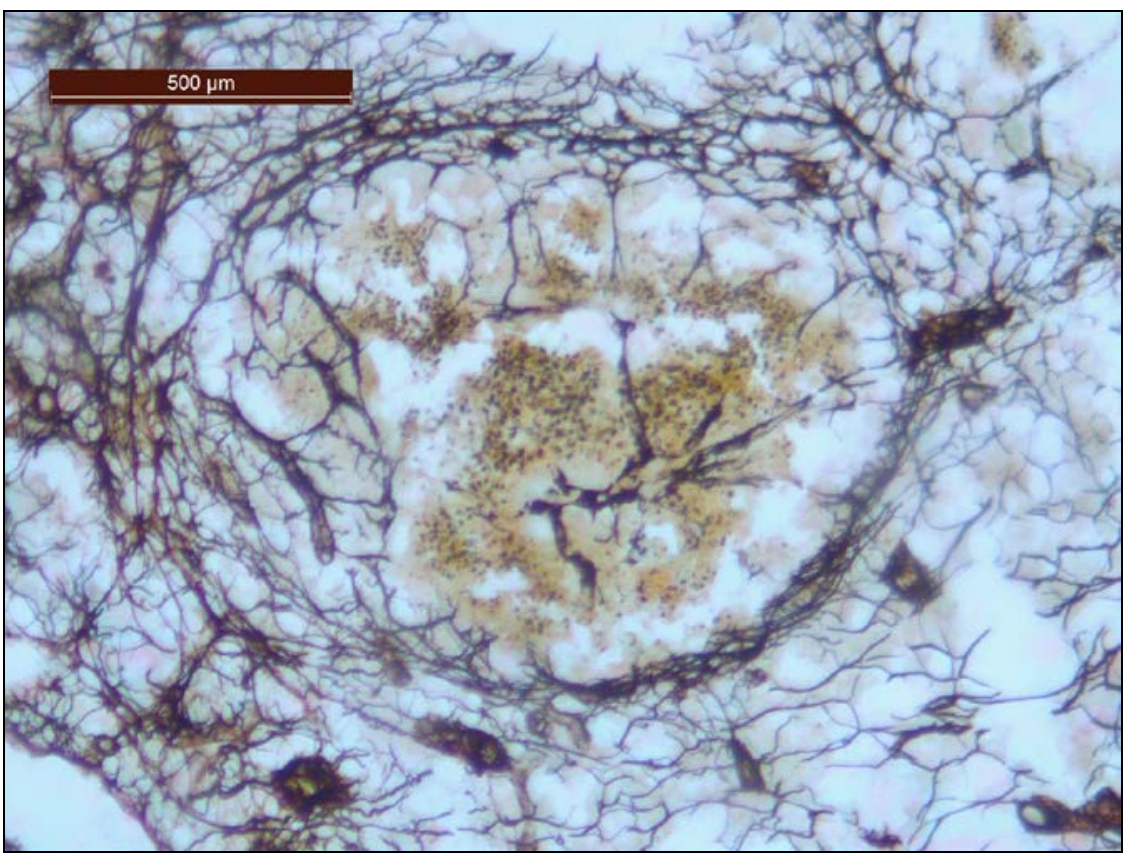

Рис. 9. Лимфатические узелки в паренхиме средостенного каудального лимфатического узла: импрегнация азотнокислым серебром

Установленная нами мозаичность структуры паренхимы лимфатических узлов верблюда может определяться рядом их структурно-функциональных особенностей. Значительное развитие в каркасе лимфатических узлов верблюда гладкой мускулатуры, вероятно, является фактором, обеспечивающим процесс принудительной внутриузловой лимфоциркуляции, что дает возможность для быстрого и глубокого проникновения в паренхиму узлов ан- тигенпрезентирующих клеток, в результате чего очаги клональной пролиферации Т- и В-лимфоцитов могут формироваться как в поверхностных, так и глубоких участках паренхимы.

С другой стороны, мозаичная структура паренхимы в лимфатических узлах верблюда может быть связана с наличием у данного вида млекопитающих особого типа лимфоснабжения, который также характерен для лимфатических узлов слонов, дельфи- 
нов, носорогов и свиней (Cave and Aumonier, 1962a, 1962b; Moskov, 1969; Hoshi et al., 1986). Вышеуказанный тип лимфоснабжения характеризуется наличием внутри сильноразвитых капсулярных трабекул I типа лимфатических цистерн и интратрабекулярных лимфатических каналов, которые одновременно сообщаются как с подкапсулярным, так и глубокими или внутренними синусами. В результате этого антигенпрезентирующие клетки проникают одномоментно в поверхностные и глубокие слои паренхимы, вызывая развитие очагов клеточной пролиферации лимфоцитов, как под капсулой, так и в других, более удаленных участках паренхимы, вдоль синусов, сопровождающих капсулярные трабекулы. В то же время зона аккумуляции плазмоцитов и синтеза антител (мозговые тяжи) формируются вдоль синусов мышечных трабекул II типа, которые, вероятно, являются истоком для эфферентных лимфатических сосудов.

Исходя из вышеуказанного, формирование всесторонне обоснованной концепции строения паренхимы лимфатических узлов у верблюда невозможно без проведения исследований структуры и взаимоотношения внутриузловой системы лимфатических пространств, кровеносных сосудов и микроциркуляторного русла.

Таким образом, основными особенностями внутриузловой лимфоциркуляции в лимфатических узлах верблюда является наличие в соединительнотканном каркасе узлов сократительных элементов, а также, вероятно, дополнительных структурных механизмов, которые обеспечивают одновременное поступление антигенпрезентирующих клеток как в поверхностные, так и глубокие участки паренхимы узлов. Наиболее развитым компонентом лимфоидных долек паренхимы лимфатических узлов половозрелого одногорбого верблюда являются зоны аккумуляции плазмоцитов и синтеза антител (комплекс мозговых тяжей).
Совокупный относительный объем мозговых тяжей в лимфатических узлах различных групп является относительно стабильной величиной и варьирует от $19 \%$ до $24 \%$, за исключением подколенного лимфатического узла, объем мозговых тяжей в котором достигает почти $37 \%$.

Зоны клональной пролиферации обеих популяций лимфоцитов развиты в меньшей степени, чем мозговые тяжи, и имеют практически одинаковые показатели относительно объема. Относительный объем зон клональной пролиферации Т-лимфоцитов варьирует от $8 \%$ до 16\%, а В-лимфоцитов от 9\% до 18\%. (табл.).

В поверхностных соматических и висцеральных лимфатических узлах верблюда зоны клональной пролиферации В-лимфоцитов развиты в несколько большей степени, чем Т-зоны (на 1$4 \%$ ), а в глубоких соматических и сомато-висцеральных узлах, наоборот, преобладают зоны клональной пролиферации Т-лимфоцитов (на 2-3\%). В целом в большинстве соматических и соматовисцеральных лимфатических узлов относительный объем зон пролиферации обеих популяций лимфоцитов примерно соответствует объему зон аккумуляции плазмоцитов и синтеза антител. То есть степень развития лимфатических узелков и единиц глубокой коры соответствует степени развития комплекса мозговых тяжей. В висцеральных лимфатических узлах совокупный относительный объем зон пролиферации обеих основных популяций лимфоцитов на 10-20\% превышает объем мозговых тяжей. Относительный объем зон транзита и межклеточного взаимодействия в исследованных лимфатических узлах в 1,5-5,0 раз меньше, чем объем мозговых тяжей. Вышеуказанная зона наиболее развита в сомато-висцеральных лимфатических узлах, несколько меньше в висцеральных и большинстве соматических узлов, за исключением подмышечного, где данный показатель минимален (4,2\%).

\section{Таблица}

Относительный объем отдельных структурных компонентов (специализированных клеточных зон) в лимфоидных дольках лимфатических узлов верблюда $(\mathrm{V}, \%, \mathrm{M} \pm \mathrm{m}, \mathrm{n}=6)$

\begin{tabular}{|c|c|c|c|c|c|}
\hline \multirow{3}{*}{ Лимфатический узел } & & \multicolumn{4}{|c|}{ Лимфоидные дольки (компартменты) } \\
\hline & & $\begin{array}{l}\text { зона транзита и } \\
\text { межклеточного } \\
\text { взаимодействия }\end{array}$ & $\begin{array}{c}\text { зона клональной } \\
\text { пролиферации } \\
\text { Т-лимфоцитов }\end{array}$ & $\begin{array}{c}\text { зона клональной } \\
\text { пролиферации } \\
\text { В-лимфоцитов }\end{array}$ & $\begin{array}{c}\text { зона аккумуляции } \\
\text { плазмоцитов, } \\
\text { синтеза антител }\end{array}$ \\
\hline & & II & III & IV & VII \\
\hline \multicolumn{6}{|c|}{ Соматические поверхностные } \\
\hline Подчелюстной & $a$ & $5,00 \pm 0,41^{b, d}$ & $11,05 \pm 0,41^{b, e-h}$ & $12,78 \pm 0,58^{b, c, g, h}$ & $19,63 \pm 0,55^{b-d, f, g}$ \\
\hline Поверхностный шейный & $b$ & $3,13 \pm 0,31^{a, c, d, h}$ & $8,05 \pm 0,31^{a, c, d, e-h}$ & $9,10 \pm 0,35^{a, d, e-h}$ & $22,98 \pm 0,7^{a, d, h}$ \\
\hline \multicolumn{6}{|c|}{ Соматические глубокие } \\
\hline Подмышечный & $c$ & $4,83 \pm 0,44^{b, d}$ & $12,03 \pm 0,43^{b, d, e, h}$ & $10,28 \pm 0,36^{a, d, e-h}$ & $21,99 \pm 0,44^{a, d, f, h}$ \\
\hline Подколенный & $d$ & $4,20 \pm 0,45^{a-c, g, h}$ & $9,99 \pm 0,36^{b, c, e, h}$ & $12,25 \pm 0,41^{b, c, e, g, h}$ & $26,95 \pm 0,53^{a-c, e-h}$ \\
\hline \multicolumn{6}{|c|}{ Сомато-висцеральные } \\
\hline Медиальный заглоточный & $e$ & $4,15 \pm 0,30^{f, h}$ & $15,93 \pm 0,53^{a-d, g, h}$ & $13,93 \pm 0,38^{b-d, f-h}$ & $20,95 \pm 0,29^{d, f f-h}$ \\
\hline Медиальный подвздошный & $f$ & $6,10 \pm 0,33^{b, e}$ & $15,03 \pm 0,35^{a-d}$ & $12,10 \pm 0,48^{b, c, e, g, h}$ & $24,28 \pm 0,31^{a, c-e, g, h}$ \\
\hline \multicolumn{6}{|c|}{ Висцеральные } \\
\hline Каудальный средостенный & $g$ & $5,33 \pm 0,46^{b, d}$ & $14,00 \pm 0,35^{a-d, e}$ & $16,88 \pm 0,43^{a-f}$ & $22,93 \pm 0,42^{a, d-f, h}$ \\
\hline Тощей кишки & $h$ & $5,73 \pm 0,28^{b, e, d}$ & $14,15 \pm 0,43^{a-d, e}$ & $17,93 \pm 0,47^{a-f}$ & $19,05 \pm 0,37^{b-g}$ \\
\hline
\end{tabular}

Примечание: латинскими буквами обозначена статистическая вероятность разницы $\mathrm{P}<0,05$ относительного объема (V\%) в пределах отдельных групп структурных компонентов (I-VII) в различных лимфатических узлах $(a-h)$.

Таким образом, лимфоидная паренхима в лимфатических узлах верблюда, как и соответствующий компонент данных органов у других видов млекопитающих, имеет четко выраженные признаки зональной специализации и интеграции. Участки паренхимы, которые в ряде работ обозначаются как анодулярная плотная лимфоидная ткань (Abdel-Magied, 2001, Saliman and Mazher, 2005), являются, по сути, зонами транзита лимфоцитов и межклеточного взаимодействия, в совокупности с зонами клональной пролиферации Т-лимфоцитов, первые из которых, как правило, примыкают к перитрабекулярным синусам трабекул I типа, а вторые расположены в более глубоких участках паренхимы. Диффузная лимфоидная ткань представляет собой совокупность мозговых тяжей, которые обеспечивают аккумуляцию плазмоцитов и синтез антител, а в лимфатических узелках, как известно, происходит клональная пролиферация В-лимфоцитов и образование клеток памяти (Rouse et al., 1984; Palm et al., 2016).
Как и у других млекопитающих, функциональные зоны паренхимы лимфатических узлов верблюда интегрированы в лимфоидные дольки или компартменты, которые имеют особый мозаичный характер расположения, что связано с рядом уникальных черт строения соединительнотканного остова узлов, а также со спецификой лимфо- и кровоснабжения узлов и внутриузловой лимфо- и гемодинамикой.

\section{Выводы}

Основными морфофункциональными характеристиками паренхимы лимфатических узлов одногорбого верблюда являются: отсутствие морфологической полярности и слоистости данного структурного компонента, а также, соответственно, признаков концентрации лимфоидной ткани в направлении устья афферентных лимфатических сосудов; тотальный губкообразный принцип 
строения лимфоидной ткани в виде комплекса незавершенных округло-овальных паренхиматозных фрагментов, разделенных широкими лимфатическими пространствами (синусами). Соединительнотканный остов лимфатических узлов верблюда отличается наличием сильно развитой внутриузловой системы капсулярных трабекул двух типов - основных или двуслойных соединительнотканно-мышечных (I тип) и дочерних однослойных, построенных из глакомышечных клеток (II тип). Трабекулы I типа содержат в своем составе лимфатические сосуды и лимфатические цистерны. Степень развития соединительнотканного остова в узлах различных групп значительно варьирует, что максимально выражено в поверхностных соматических лимфатических узлах и минимально - в висцеральных.

Основная масса лимфатических пространств в паренхиме лимфатических узлов, за исключением мозговых синусов, располагается вдоль трабекул, наиболее крупными при этом являются синусы, сопровождающие трабекулы I типа, затем следуют синусы трабекул II типа и синусы, расположенные в мозговом веществе лимфоидных долек.

Паренхима лимфатических узлов верблюда имеет четко выраженную зональную специализацию, а также дольковую (компартментную) структуру. Структурно-функциональные единицы лимфатических узлов верблюда устроены в соответствии с общими принципами морфофункциональной организации данных субъединиц у млекопитающих с наличием трех основных типов специализированных зон: транзита и межклеточной кооперации, клональной пролиферации Т- и В-лимфоцитов, аккумуляции плазмоцитов и антителообразования. Объемные количественные характеристики основных структурных компонентов лимфоидных долек в узлах различных групп являются относительно стабильными. Максимальный относительный объем имеют зоны аккумуляции плазмоцитов и антителообразования, затем следуют зоны клональной пролиферации Т- и В-лимфоцитов. Минимальный относительный объем характерен для зон транзита и межклеточной кооперации.

Для лимфоидных долек (компартментов) лимфатических узлов верблюда характерен диффузный (мозаичный) принцип расположения в пределах паренхимы в целом, а также полярный принцип строения с преимущественной локализацией зон транзита и межклеточного взаимодействия с лимфатическими узелками вдоль перитрабекулярных синусов трабекул I типа и концентрацией мозговых тяжей (зон аккумуляции плазмоцитов и синтеза антител) в направлении перитрабекулярных синусов трабекул II типа, которые, вероятно, являются «истоками» эфферентных лимфатических сосудов. Зоны клональной пролиферации Т-лимфоцитов непосредственно с перитрабекулярными синусами не граничат и концентрируются в глубоких слоях паренхимы, формируя основу или центральную зону ее компартментов. Дальнейшие исследования структуры лимфатических узлов у одногорбого верблюда будут направлены на выяснение возрастных аспектов их морфогенеза, а также закономерностей строения и взаимоотношения внутриузловой системы лимфатических пространств и различных типов кровеносных сосудов.

\section{References}

Abdel-Magied, E. M., Taha, A. M., Al-Qarawi, A. A., \& Elfaki, M. G. (2001). The parotid, mandibular and lateral retropharyngeal lymph nodes of the camel (Camelus dromedarius). Anatomia Histologia Embryologia, 30(4), 199-203.

Ager, A. (2017). High endothelial venules and other blood vessels: Critical regulators of lymphoid organ development and function. Frontiers in Immunology, 8(3), 1-16.

Andrian, U. H., \& Mempel, T. R. (2003). Homing and cellular traffic in lymph nodes. Nature Reviews Immunology, 3, 867-878

Belisle, C., \& Sainte-Marie, G. (1981). Tradimentional study of the deep cortex of the rat lymph node. III. Morphology of the deep cortex units. The Anatomical Record, 199(2), 213-226.

Butler, J., Sawtell, A., Jarrett, S., Cosgrove, J., Leigh, R., Timmis, J., \& Coles, M. (2016). Imaging immunity in lymph nodes: Past, present and future. Advances in Experimental Medicine and Biology, 915, 329-346.
Cave, A. J. E., \& Aumonier, F. J. (1962a). Elephant and rhinoceros lymph-node histology. Journal Rino Mikroskopik, 80, 209-214.

Cave, A. J. E., \& Aumonier, F. J. (1962b). Lymph node structure in the sumatran rhinoceros. Journal Rino Mikroskopik, 81, 73-77.

Chandrasekaran, S., \& King, M. R. (2014). Microenvironment of tumor-draining lymph nodes: Opportunities for liposome-based targeted therapy. International Journal of Molecular Sciences, 15(11), 20209-20239.

De Bruyn, P. P., \& Cho, Y. (1990). Structure and function of high endothelial postcapillary venules in lymphocyte circulation. Current Topics in Pathology, 84(1), 85-101.

Gavrilin, P. N. (1999). Modificatsiya sposoba impregnatsii serebrom po Futy gistotopogramm organov krovetvoreniya, izgotovlennyih na microtome-kriostate [Modification of the silver impregnation method according to Fut histotopograms of hemopoietic organs made on a microtome cryostat]. Vestnik Morphologii, 5(1), 106-108 (in Russian).

Gavrilin, P. N., Gavrilina, O. G., \& Kravtsova, M. V. (2017). The compartments of the parenchyma of the lymph nodes in the newborn domestic bull (Bos taurus). Regulatory Mechanisms in Biosystems, 8(2), 169-178.

Gavrilin, P. N., Masjuk, M. O, \& Tishkina, N. N. (2014). Osoblivosti makroskopichnoi strukturi limfatichnih vuzliv svini sviyskoi [Features of macroscopic structure of lymph nodes of the domestic pig]. Nauchno-Tehnicheskiy Byuleten Nauchno-Issledovatelskogo Tsentra Biobezopasnosti i Ekologicheskogo Kontrolya Resursov APK, 2(1), 32-37 (in Ukrainian).

Gavrilin, P. N., Perepechaeva, N. H., \& Tishkina, N. N. (2015). Vozrastnyie preobrazovaniya gistoarhitektoniki parenhimyi limfaticheskih uzlov u krupnogo rogatogo skota $\mathrm{v}$ postnatalnyiy period ontogeneza [Age transformations of histoarchitectonics of parenchyma of lymph nodes in cattle in the postnatal period of ontogenesis]. Biologiya Tvarin, 17(1), 29-35 (in Russian).

Gavrilin, P. N., Prokushenkova, O. H., Masjuk, D. N., \& Perepechaeva, N. H. (2013). Peculiarities of structural and functional organization of Domestic Bull's lymph nodes parenchyma (Bos primigenius taurus L.). Naukovyj Visnyk Nycional'nogo Universytetu Bioresursiv i Pryrodokorystuvannja Ukrai'ny, 188(1), 92-101.

Gretz, J. E., Anderson, C. C., \& Shaw, S. (1997). Cords, channels, corridors and conduits, critical architectural facilitating cell interactions in the lymph node cortex. Immunological Reviews, 156, 11-24.

Gunnes, G., Press, C., Tverdal, A., \& Landsverk, T. (1998). Compartments within the lymph node cortex of calves and adult cattle differ in the distribution of leukocyte population: An immunohistochemical study using computer-assisted morphometric analysis. Developmental and Comparative Immunology, 22(1), 111-123.

Hoshi, N., Hashimoto, Y., Kitagawa, H., Kon, Y., \& Kudo, N. (1986). Histological and immunohistochemical studies on the architecture of lymph nodes in pig. Japan Journal Veterinary Science, 48(6), 1097-1107.

Houston, S. A., Cerovic, V., Thomson, C., Brewer, J., Mowat, A. M., \& Milling, S. (2016). The lymph nodes draining the small intestine and colon are anatomically separate and immunologically distinct. Mucosal Immunology, 9(2), 468-478.

Ikomi, F., Kawai, Y., \& Ohhashi, T. (2012). Recent advance in lymph dynamic analysis in lymphatics and lymph nodes. Annals of Vascular Diseases, 5(3), 258-268.

Iwasaki, R., Mori, T., Ito, Y., Kawabe, M., Murakmi, M., \& Maruo, K. (2016). Computed tomographic evaluation of presumptively normal canine sternal lymph nodes. Journal of the American Animal Hospital Association, 52(6), 371-377.

Kaldjian, E. P., Gretz, J. E., Anderson, A. O., Shi, Y., \& Shaw, S. (2001). Spatial and molecular organization of lymph node T cell cortex: A labyrinthine cavity bounded by an epithelium-like monolayer of fibroblastic reticular cells anchored to basement membrane-like extracellular matrix. International Immunology, 13(10), 1243-1253.

Katakai, T., Hara, T., \& Lee, J. H. (2004). A novel reticular stromal structure in lymph node cortex: An immuno-platform for interactions among dendritic cells, T cells and B cells. International Immunology, 16(8), 1133-1142.

Kelly, R. H. (1975). Functional anatomy of lymph nodes. The paracortical cords. Intemational Archives of Allergy and Immunology, 48(6), 836-849.

Konenkov, V. I., Shkyrat, G. A., \& Kolesnikov, A. P. (2008). Limfaticheksij uzel: Morfofunkcional'naja harakteristika i mezhkletochnaja kooperacija [Lymph node: Morphofunctional characteristic and intercellular cooperation]. Vestnik Limfologii, 4, 35-43 (in Russian).

Kowala, M. C., \& Schoefi, G. I. (1986). The popliteal lymph node of the mouse: Intemal architecture, vascular distribution and lymphatic supply. Journal of Anatomy, 148(1), 25-46.

Margaris, K. N., \& Black, R. A. (2012). Modelling the lymphatic system: Challenges and opportunities. Journal of the Royal Society Interface, 69, 1-12.

Mebius, R. E. (2003). Organogenesis of lymphoid tissues. Nature Reviews Immunology, 3(4), 292-303.

Moskov, M., Schiwatschewa, T., \& Bonev, S. (1969). Vergleichshistologische Untersuchung der Lymphknoten der Sauger. Die lymphknoten des Dolphins. Anatomischer Anzeiger, 124, 49-67. 
Olson, M. R., McDermott, D. S., \& Varga, S. M. (2012). The initial draining lymph node primes the bulk of the $\mathrm{CD}_{8} \mathrm{~T}$ cell response and influences memory $\mathrm{T}$ cell trafficking after a systemic viral infection. PLOS Pathogens, 8(12), 1-15.

Palm, E. A., Friedrich, C. H., \& Kleinau, S. (2016). Nodal marginal zone B cells in mice: A novel subset with dormant self-reactivity. Scientific Reports, 6, 27687.

Platt, A. M., \& Randolph, G. J. (2013). Dendritic cell migration through the lymphatic vasculature to lymph nodes. Advances in Immunology, 120, 51-68.

Rouse, R. V., Reichert, R. A., Gallatin, W. M., Weissman, I. L., \& Bucher, E. C. (1984). Localization of lymphocyte subpopulation in peripheral lymphoid organs: Directed lymphocyte migration and segregation into specific microenvironments. American Journal of Anatomy, 170, 391-405.

Ruddle, N. H. (2016). High endothelial venules and lymphatic vessels in tertiary lymphoid organs: Characteristics, functions, and regulation. Frontiers in Immunology, 9(7), 1-7.

Sainte-Marie, G. (2010). The lymph node revisited: Development, morphology, functioning, and role in triggering primary immune responses. The Anatomical Record, 293(2), 32-37.

Saliman, S. M., \& Mazher, K. M. (2005). Light and electron microscopic studies on some lymph nodes of the adult one-humped camel (Camelus dromedarius). Beni Suef Veterinary Medicine Journal, 15(2), 9-13.
Taher, E.-S. M., El-Sakhawy, M. A., Moussalam, E.-S., Moussa, M. H. G., ElBargeesy, G. (1989). Studies of the lymphoid tissue of lymph nodes of one humped camel fetuses (Camelus dromedarius). Egypt Journal Histology, 12(1), 23-33.

Vyrenkov, Y. E., Shishlo, V. K., Antropova, J. G., \& Ryzhova, A. V. (1995). Sovremennye dannye o strukturno-funkcional'noj organizacii limfaticheskogo uzla [Modern data on the structural and functional organization of the lymph node]. Morphology, 103(3), 34-40 (in Russian).

Willard-Mack, C. L. (2006). Normal structure, function, and histology of lymph nodes. Toxicologic Pathology, 34(5), 409-424.

Zelenevsky, N. V. (2013). Mezhdunarodnaja veterinarnaja anatomicheskaja nomenklatura na latinskom i russkom jazykah. Nomina Anatomica Veterinaria [International veterinary anatomical nomenclature in Latin and Russian. Nomina Anatomica Veterinaria]. Mir, Sankt-Peterburg (in Russian).

Zidan, M., \& Pabst, R. (2002). Detection of apoptosis in the lymphoid organs of the dromedary camel. Journal of Camel Practice and Research, 9(2), 163-166.

Zidan, M., \& Pabst, R. (2012). Histological, histochemical and immunohistochemical study of the lymph nodes of the one humped camel (Camelus dromedarius). Veterinary Immunology and Immunopathology, 145(1-2), 191-198. 